$\mathrm{DOE} / \mathrm{ER} / 13631--18$

DE92 008709

\title{
PHOTOCHEMICAL ENERGY CONVERSION BY MEMBRANE-BOUND \\ PHOTOREDOX SYSTEMS
}<smiles>COC#N</smiles>

Progress Report

for the Period July 1., 1989 to March 1, 1992

Gordon Tollin

Department of Biochemistry

University of Arizona

Tucson, Arizona 85721

March 1, 1992

Prepared for: THE U.S. DEPARTMENT OF ENERGY

AGREEMENT NO. DE-FG02-86ER13631

\begin{abstract}
NOTICE
This report was prepared as an accelnt of work sponsored by the United States Government. Neither the United States nor the Department of Energy, nor any of their employees, makes any warranty, express or implied, or assumes any legal liability or responsibility for the accuracy, completeness, or usefulness of any information, apparatus, product or process disclosed or represents that its use would not infringe privately-owned rights.
\end{abstract}




\section{INTRODUCTION}

Most of our effort during the past grant period has been directed towards investigating electron transfer processes involving redox proteins at lipid bilayer/aqueous interfaces. This theme, as was noted in our previous three year renewal proposal, is consistent with our goal of developing biomimetic solar energy conversion systems which utilize the unique properties of biological electron transfer moleciles. Thus, small redox proteins such as cytochrome $\underline{\mathrm{c}}$, plastocyanin and ferredoxin function in biological photosynthesis as mediators of electron flow between the photochemical systems localized in the membrane, and more complex soluble or membrane-bound redox proteins which are designed to carry out specific biological tasks such as transbilayer proton gradient formation, dinitrogen fixation, ATP synthesis, dihydrogen synthesis, generation of strong reductants, etc. In these studies, we have utilized two principal experimental techniques, laser flash photolysis and cyclic voltammetry, both of which permit direct measurements of electron transfer processes.

All previous agreement requirements have been complied with. The Principal Investigator (G. Tollin) has devoted approximately $20 \%$ of his time during the academic year, and $50 \%$ of his time during the summer, to this project. This level of effort will continue during the remainder of the current term.

Fourteen full-length papers have been published, are in press, or have been submitted as a consequence of work done during this grant period (see listing below). Reprints and preprints are attached to this Report. We believe that we have made extraordinary progress over the past three years in developing biomimetic systems for photochemical energy 
storage. Especially noteworthy are the following accomplishments: i. we have achieved efficient photoinduced transbilayer electron transport from reduced cytochrome in the inner aqueous compartment of vesicles to oxidized ferredoxin in the outer aqueous phase, thereby storing approximately $0.7 \mathrm{~V}$ in the products; this is a close analog of the electron transport process which occurs in green plant Photosystem I; ii. we have devised a system utilizing a small organic molecule (EDTA) as a sacrificial donor in a two-photoreaction process which results in transbilayer electron transport to ferredoxin; this mimics the two light reactions in photosynthesis and generates a strong reductant; iii. using sulfonated hydroquinones and quinones as electron donors and acceptors, we have accomplished the photogeneration of a pH gradient across a bilayer membrane; such transbilayer pH gradient formation is a key energy storage process in biology; iv. we have developed a novel method of modifying the surface of a metal electrode (using a lipid bilayer) which dramatically improves electrochemical coupling to redox proteins, thus providing a possible new approach to the conversion of photon energy into electrical energy. A more detailed description of the scientific progress made during this grant period follows.

\section{SUMMARY OF SCIENTIFIC PROGRESS}

\section{1- Chlorophyll photosensitized reduction of cytochrome $c$ and cytochrome c oxidase}

In previous studies supported by DOE utilizing chlorophyll-containing lipid bilayer vesicles (Senthilathipan \& Tollin, Photochem. Photobiol. 43, 545, 1986; Fang \& Tollin, Photochem. Photobiol. 47, 741, 1988; 47, 751, 1988), we showed that the herne protein cytochrome $\underline{c}$, located in the outer aqueous compartment, could be reduced by an electron 
originating in the triplet state of chlorophyll dissolved in the bilayer, either directly by electrostatically binding the cytochrome to the bilayer surface, or indirectly via a quinone mediator. We have now extended this work in two ways: $i$. we have improved the efficiency of cytochrome $\underline{\mathbf{c}}$ reduction by approximately a factor of two by using pairs of quinones as mediators (Chamupathi \& Tollin, 1990; ref. 1); ii. we have coupled chlorophyllphotosensitized cytochrome $\underline{\mathrm{c}}$ reduction to the reduction of membrane-bound cytochrome c oxidase (Chamupathi et al., 1990; ref. 2), the latter being one of the major energytransducing proteins in biology.

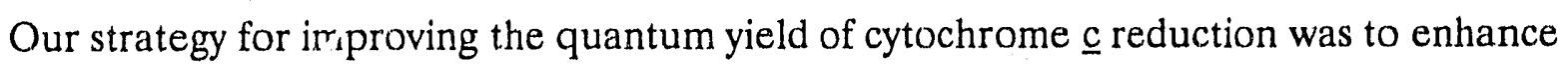
the efficiency of electron flow from the membrane interior (where the chlorophyll is located) to the outer aqueous phase (where the cytochrome is located). We accomplished this by utilizing a lipophilic quinone as the primary electron acceptor from triplet chlorophyll within the bilayer, and a hydrophilic quinone in the aqueous phase as a secondary acceptor from the reduced primary acceptor quinone, which then served as the direct mediator of electron flow to the cytochrome. This allowed us to achieve more effective charge separation across the membrane-water interface. Overall, our measurements showed that approximately $40 \%$ of the chlorophyll triplet molecules generated by the laser flash were converted into separated products (i.e. chlorophyll cation radical in the membrane and reduced cytochrome in the aqueous phase). Inasmuch as the cytochrome and the hydrophilic quinone in these experiments were present only in the outer aqueous compartment, those triplets formed in the inner monolayer of the vesicle did not participate in the electron transfer events leading to cytochrome reduction. Thus, the actual efficiency was probably closer to $100 \%$. Although 
reverse electron transfer (i.e. cytochrome reoxidation and chlorophyll cation radical reduction) did eventually occur, the rate of this process was quite slow (halftime $140 \mathrm{~ms}$ ), allowing ample time for additional reactions involving the products of energy storage to proceed (for example, cytochrome oxidase reduction; see below). It should also be noted that this strategy of using lipophilic/hydrophilic mediator pairs is not specific for cytochrome reduction, and thus represents a general method for enhancing the efficiency of electron flow from a membrane interior to an aqueous compartment. Indeed, it is utilized in vivo during natural photosynthesis for precisely this same purpose!

In order to accomplish the construction of an effective light-driven electron transport chain in an artificial membrane which resulted in the deposition of electrons into a membrane-bound energy-transducing redox protein, analogous to events occurring during natural photosynthesis, we incorporated cytochrome $\underline{\mathrm{c}}$ oxidase into chlorophyll-containing lipid bilayer vesicles which were capable of reducing cytochrome $\underline{c}$ in the aqueous phase via a quinone mediator. Using time-resolved laser spectroscopy, we clearly showed that sequential electron transfer occurred from triplet chlorophyll to cytochrome oxidase, with intermediate electron flow through the quinone and the cytochrome (i.e. a four component electron transfer chain). The overall yield, based on the quenching of the chlorophyll triplet state population, was $14 \%$ (again, however, we note that only the outer membrane surface was involved). Back electron transfer regenerating starting materials was exceedingly slow in this system (halftime $1 \mathrm{~s}$ ). Although we did not carry this experiment further to show that proton gradient formation and ATP synthesis could be accomplished with this system, there is no reason to believe that this could not be done, given the appropriate experimental 
protocol. Indeed, such processes have been reconstituted in lipid bilayer vesicles in other laboratories (cf. for example, Prochaska \& Wilson, Arch. Biochem. Biophys. 290, 179 (1991)). We therefore feel that these results are of considerable significance for the future development of effective biomimetic solar energy conversion strategies.

\section{2- Chlorophyll photosensitized vectorial electron transfer across a lipid bilayer from reduced} cytochrome to oxidized ferredoxin

One of the key energy storage events in natural photosynthesis is the light-induced separation of redox equivalents across a hydrophobic harrier provided by a lipid bilayer membrane. In green plants, this involves the oxidation of either reduced cytochrome or reduced plastocyanin (the latter is a copper protein) on one side of the membrane, and reduction of the soluble iron-sulfur protein ferredoxin on the other side. During the current grant period, we have accomplished this in our chlorophyll-vesicle systems (Zhao \& Tollin, 1991a; ref. 4). This involved incorporating reduced cytochrome $\underline{\mathrm{c}}$ in the inner aqueous compartment of negatively charged vesicles, oxidized ferredoxin in the outer aqueous phase, and using the low potential positively charged viologen analog propylene diquat as a mediator between triplet chlorophyll and ferredoxin. Using both steady-state and laser flash methods, we demonstrated that illumination of chlorophyll results in ferredoxin reduction and cytochrome oxidation. The overall yield, based on triplet chlorophyll quenched, was $11 \%$. This was limited by three factors: i. an opposing transmembrane potential which was established upon addition of the highly negatively charged ferredoxin to the outer compartment, and which was enhanced upon electron flow from inside to outside; ii. the build-up of oxidized cytochrome in the inner compartment, which functioned as an electron 
acceptor from triplet chlorophyll and thus acted to inhibit electron flow from inside to outside, ' $s$ well as to limit the reducing equivalents which could be deposited in ferredoxin to one-half of the added cytochrome; iii. the rather poor chlorophyll triplet quenching ability of propylene diquat. The first two of these limitations have been overcome by subsequent work done during the present grant period; the third is an objective of the next grant period (see Proposed Research below). The limitation imposed by the transmembrane potential was mitigated by the addition of the ionophore valinomycin plus potassium ion into the system (Zhao \& Tollin, 1991b; ref. 5). This served to neutralize the opposing transmembrane potential by allowing potassium ion to flow through the bilayer, and increased the overall yield by a factor of two. The limitation involving oxidized cytochrome generation was overcome by the incorporation of a second photosystem into the inner compartment (Zhao \& Tollin, manuscripts submitted, 1991a,b; ref. 13,14). This second photoreaction involved a flavin analog (FMN) plus a sacrificial electron donor (EDTA), which upon blue light excitation generated a strong reductant (the flavin semiquinone) as a result of triplet quenching by EDTA. The flavin semiquinone then served to reduce oxidized cytochrome $\underline{\mathrm{c}}$ formed in the inner compartment via electron transfer to chlorophyll cation radical. This prevented the inhibition of electron flow caused by the accumulation of the oxidized cytochrome. As a consequence of this, the limiting factor in the generation of reducing power was no longer the amount of cytochrome which could be incorporated into the inner compartment, but rather the amount of EDTA which could be so incorporated. Inasmuch as the latter molecule is smaller and more soluble than cytochrome $\underline{\mathbf{c}}$, we were able to 
increase the reducing capacity of the system sufficiently so that all of the ferredoxin added to the outer compartment could be photoreduced under steady-state illumination with white light. This system has several interesting features with regard to solar energy conversion: it permits the storage across the bilayer of an appreciable amount of electromagnetic energy (approximately $0.7 \mathrm{~V}$ ); it utilizes a small organic molecule (EDTA) as a sacrificial electron donor for the generation of a strong reductant (reduced ferredoxin), which can be coupled to dinitrogen fixation or dihydrogen production via the appropriate enzymes; it utilizes two photoreactions, as does natural photosynthesis. We thus believe this constitutes a major achievement in the development of biomimetic solar conversion systems!

3- Photochemical generation of transbilayer proton gradients in chlorophyll-vesicle systems

Another key event in natural photosynthesis is the generation of a transmembrane protor gradient coupled to photochemical electron transfer. This is used in vivo for the synthesis of ATP, as well to drive other energy-requiring processes such as ion transport. We have now achieved this biomimetically in our chlorophyll-vesicle systems (Zhao \& Tollin, manuscript in press; ref. 10). Our strategy involved the asymmetric placement of sulfonated quinones and hydroquinones into the two aqueous phases of a bilayer vesicle system. Using both laser flash and steady-state methods, we demonstrated that illumination generated the chlorophyll triplet, which reduced the quinone at the outer membrane-water interface forming the quinone anion radical and the chlorophyll vation radical. Hole migration across the bilayer allowed the chlorophyll cation radical to move to the inner surface, where it was then reduced by the hydroquinone forming the hydroquinone cation radical in the aqueous phase and regenerating chlorophyll in the membrane. The overall 
efficiency of this vectorial electron flow across the bilayer was $39 \%$, based on chlorophyll triplet quenching. The following quinone radical disproportionation reactions were then responsible for generating a proton gradient across the bilayer:

$$
\left.\begin{array}{c}
2 \mathrm{Q}^{*}+2 \mathrm{H}^{+} \rightarrow \mathrm{Q}+\mathrm{H}_{2} \mathrm{Q} \\
\mathrm{H}_{2} \mathrm{Q}^{+\cdot} \rightarrow \mathrm{Q}+2 \mathrm{H}^{+} \\
2 \mathrm{Q}^{*}+2 \mathrm{H}^{+} \rightarrow-\mathrm{Q}+\mathrm{H}_{2} \mathrm{Q}
\end{array}\right\} \text { (outside; net uptake of } \mathrm{H}^{+} \text {) }
$$

The indicator dye, bromcresol purple, was used in both steady-state and laser flash experiments to observe the $\mathrm{pH}$ changes produced in this system. Quantitation of these $\mathrm{pH}$ effects led to the conclusion that a single laser flash caused a proton concentration decrease of $0.2 \mu \mathrm{M}$ in the outer compartment, and the release of an equal quantity of protons in the inner compartment (note that because the volume of the inner phase is only $1 / 1000$ that of the outer phase, the $\mathrm{H}^{+}$concentration change was correspondingly larger, i.e. $\approx 200 \mu \mathrm{M}$ ). Thus, a large pH gradient was produced across the bilayer. Although, in our experiments, we did not utilize this photogenerated $\mathrm{pH}$ gradient for any practical purposes, it seems clear that this could be done. Again we conclude that these results have important implications for the future design of solar conversion systems, and perhaps other technologies as well. 
. - Use of lipid bilayers as electrode coatings to facilitate redox protein electrochemistry

Facile electron exchange between redox proteins and electrode surfaces has long been

a difficult problem in electrochemistry, and much effort has been expended on developing various methods of electrode surface modification to improve the efficiency of this process. During the current grant period, we have combined our extensive experience with electron transfer reactions of redox proteins located at lipid bilayer-aqueous interfaces, with the development in Tien's laboratory (Tien \& Salamon, Bioelectrochem. Bioenerg. 22, 211, 1989; Martynski \& Tien, Bioelectrochem. Bioenerg. $25,317,1991)$ of a method for coating metal surfaces with lipid bilayers, to develop a novel approach to electrode surface modification which allows direct electrochemical reactions involving redox proteins to occur with high efficiency, as well as providing a support for incorporating small molecule electron mediators which cancassist in the effective coupling of the electrode surface to the redox protein (Salamon \& Tollin, 1991a,b; Salamon \& Tollin, manuscripts in press; refs. 6,7,8,11). We have utilized this appruach to carry out cyclic voltammetry measurements with cytochrome $\underline{\mathrm{c}}$, ferredoxin, and plastocyanin which have demonstrated quite clearly that lipid bilayer-modified electrodes have electrochemical properties which are as good as or better than those obtained using other methods of electrode surface modification. By varying the lipid concentration in the bilayer, the bilayer surface charge and the ionic strength of the medium, we were able to show that attractive electrostatic interactions, as well as hydrophobic forces, are involved in the membrane-protein interactions which allow the occurrence of facile electron transfer with the electrode surface. Variation of these parameters allows us to tailor the properties of the electrode surface to match the particular 
protein which is under investigation. Thus, negatively charged proteins can be made to interact with a positively charged membrane surface, etc. This is an extremely important feature of this methodology, inasmuch as it permits the construction of electrode surfaces which display specificity in their ability to interact with redox proteins. We believe that this new approach to redox protein electrochemistry will be useful in coupling photochemical energy storage in redox proteins (as in the results described above) to the generation of electrical potentials in an external circuit. We are presently working towards this end (see Proposed Research).

\section{5- NMR studies of protein-membrane interactions}

This was one of the areas in which we proposed to work during the current grant period, as a means of obtaining structural information about protein-bilayer interactions. We have indeed attempted to carry out several NMR experiments utilizing the copper protein plastocyanin. Thus far, none of these has proven successful. We first attempted to detect paramagnetic shifts of the ${ }^{31} \mathrm{P}$ NMR signals of phospholipids upon binding oxidized plastocyanin to the membrane. This was unsuccessful. On the basis-of control experiments with simple copper chelates, we concluded that the distance between the paramagnetic copper ion which is bound within the plastocyanin molecule and the phosphorous atoms of the lipid headgroup was too large for such effects to be observed. Our next approach was to use 2-D proton NMR to detect structural changes in reduced (diamagnetic) plastocyanin upon binding of the (negatively charged) protein to micelles formed from deuterated positively charged lipids (dodecyltrimethylammonium ions). Although we were successful in obtaining well-resolved 2-D NMR spectra (NOE's) from plastocyanin solutions, we found 
that the positively charged micelles caused plastocyanin to denature. We are presently attempting to continue this work using a neutral lipid (dodecylphosphorylcholine) as the micelle-forming entity (we have shown that plastocyanin also binds to neutral lipids via hydrophobic interactions). In preliminary experiments, we have verified that this neutral lipid does not cause plastocyanin to denature, and the appropriate NMR experiments are now in progress.

\section{6- Miscellaneous}

By invitation, a review of chlorophyll photochemistry in microheterogeneous media was written (Tollin, 1991; ref. 3) for the volume "Chlorophylls", edited by H. Scheer.' This covered work done in micelles, planar lipid bilayers, lipid bilayer vesicles, microemulsions and several miscellaneous heterogeneous systems, and focussed particularly on processes relevant to energy conversion and storage.

An invitation was also received to contribute an article to "The Spectrum", which is the scientific newsletter of the Center for Photochemical Sciences at Bowling Green State University. A copy of the submitted article is appended to this report. Although, strictly speaking, this does not constitute a publication (and hence is not included in the listing below), it does provide a convenient summary of our point of view and some of our recent progress, and thus may be of use to DOE and the reviewers of this proposal. Its publication in the newsletter should considerably increase the breadth of the audience which is aware of our work.

During the present grant period we have utilized our DOE-purchased laser photolysis equipment, as well as the experience we have obtained during our DOE-funded research 
with photoinduced electron transfer processes involving redox proteins, to carry out studies of the oxidation of reduced plastocyanin and cytochrome $\underline{c}$, and the reduction of oxidized ferredoxin, by membrane preparations isolated from spinach chloroplasts (Hervas et al., manuscript in press; Hervas et al., manuscript submitted; refs. 9,12). These studies were stimulated by a visit to my laboratory of two scientists from the University of Sevilla in Spain, who had experience with steady-state kinetic measurements of these reactions. Inasmuch as the results are nct within the scientific framework of our DOE grant, I will not summarize them here. However, since we acknowledged DOE support for this work, I am appending copies of the manuscripts to this Yrogress Report and including the references in the publication list.

In the previous review of this grant, I was criticized for not involving graduate students in this research program, and relying solely on postdoctoral students. As can be noted, this situation has not changed during the current grant period, although in one of our publications (ref. 2) an undergraduate student (D.M. Moezzi) participated as a significant contributor. It is also fair to say that it is unlikely that this will change significantly in the near future. There are two principal reasons for this: i. there is a clear shortage of graduate students in biochemistry; ii. it is difficult to obtain biochemistry graduate students who are interested in pursuing research in biomimetic solar energy conversion. Although, in principle, I have access to chemistry graduate students as a consequence of having a joint appointment in the Department of Chemistry, in practice it is exceedingly rare at this university for such students to opt to work for a faculty member whose principal appointment and physical location is in the Department of Biochemistry (in fact, it has never 
happened!). In contrast to this, I continue to receive many inquiries from individuals, whose backgrounds are mainly in chemistry or biophysics, for postdoctoral positions in my laboratory to work in this area.

\section{PUBLICATIONS DURING GRAINT PERIOD}

1- Chamupathi, V.G. \& Tollin, G. Photochem. Photobiol. 51, 611-619 (1.990).

2- Chamupathi, V.G., Moezzi, D.M. \& Tollin, G. Photochem. Photobiol. 52, 883-891 (1990).

3- Tollin, G., in Chlorophylls, H. Scheer, ed., pp. 317-337, CRC Press, Boca Raton, 1991.

4- Zhao, Z.-G. \& Tollin, G. Photochem. Photobiol. 54, 113-122 (1991a).

5- Zhao, Z.-G. \& Tollin, G. Photochem. Photobiol., 54, 827-831 (1991b).

6- Salamon, Z. \& Tollin, G. Bioelectrochem. Bioenerg. 25, 447-454 (1991a).

7- Salamon, Z. \& Tollin, G. Bioelectrochem. Bioenerg. 26, 321-334 (1991b).

8- Salamon, Z. \& Tollin, G. Bioelectrochem. Bioenerg., in press.

9- Hervas, M., De la Rosa, M. \& Tollin, G. Eur. J. Biochem., in press.

10- Zhao, Z.-G. \& Tollin, G. Photochem. Photobiol, in press.'

11- Salamon, Z. \& Tollin, G. Arch. Biochem. Biophys., in press.

12- Hervas, M., Navarro, J.A. \& Tollin, G. Photochem. Photobiol, manuscript submitted.

13- Zhao, Z.-G. \& Tollin, G. Photochem. Photobiol. (1991a), manuscript submitted.

14- Zhao, Z.-G. \&. Tollin, G. Photochem. Photobiol. (1991b), manuscript submitted. 
Deskside Wall Organizer Displays 20 Reference Sheets No Tacks! No Tape! No Mess!

Quick-Eze display systems eliminate unsightly reference sheets tacked or taped to your walls. You have fast access to information you reference every day. Put rates, codes, catalogs, prices, directories, all frequenily referenced data at your fingertips.

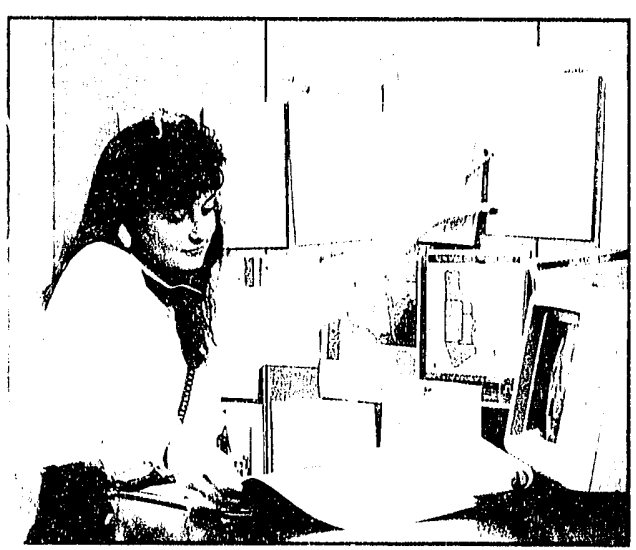

Before ...

\section{Quick-Eze... Pays It's Own Way Or Return it For A} Full Refund!

Fast access to organized, frequently referenced information! AVESTIME! Quick-Eze users estimate they save 10 minutes per day that they would have otherwise spent searching!

QUICK-EZE WILL SAVE YOU UP TO ONE HOUR PER WEEK OVER 50 HOURS PER YEAR.

\begin{tabular}{|c|c|c|c|c|c|}
\hline \multirow{2}{*}{\multicolumn{2}{|c|}{ WALL UNIT }} & \multicolumn{4}{|c|}{ Price Each \& in Quantity } \\
\hline & & 1 & 2.4 & $5-8$ & $10+$ \\
\hline Model & Capacilty & & $($ less $10 \%)$ & $(\operatorname{los} 815 \%)$ & (1088 20\%) \\
\hline WOEW20 & 20 Sheols & $\$ 58.00$ & $\$ 53.10$ & $\$ 50.15$ & $\$ 47.20$ \\
\hline PMW2O & \multicolumn{5}{|c|}{ (Optional) Velcro strip lor pangl mounting $) \$ 2.75 / E A$} \\
\hline
\end{tabular}

\section{Quick-Eze Desktop ... FAST} Reference for up to 60 sheets When desktop positioning is preferred and a larger capacity for sheet displays is needed, QUICK-EZE DESKTOP UNITS are the answer. Display 20,40, or 60 pages in one of three units available.

Cushioned bottoms prevent sliding and scratching of desik surfaces. Standard with each unit are side stops, index tabs \& 5 colors of pockets. Base design allows $10 \& 20$ pocket units to increase to 30 pocket (50 page) capacity.

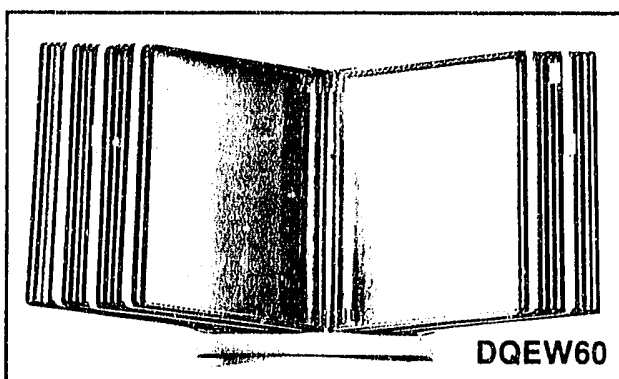

\begin{tabular}{|c|c|c|c|c|c|}
\hline \multirow{2}{*}{\multicolumn{2}{|c|}{ DESK UNIT }} & \multicolumn{4}{|c|}{ Price Each \& In Quantlty } \\
\hline & & 1 & 2.3 & 4.7 & $\theta_{4}$ \\
\hline Modal & Capacity & & (lose $10 \%$ & $108815 \%$ & (1ess 20\%) \\
\hline DOEW20 & 20 Sheots & S 69.00 & $\$ 62.10$ & 558.65 & 555.20 \\
\hline DOEW4O & 40 Sheets & 125.00 & 112.50 & 106.25 & 99.95 \\
\hline DQEW60 & 60 Sherts & 179.00 & 161.10 & 152.15 & 143.20 \\
\hline
\end{tabular}

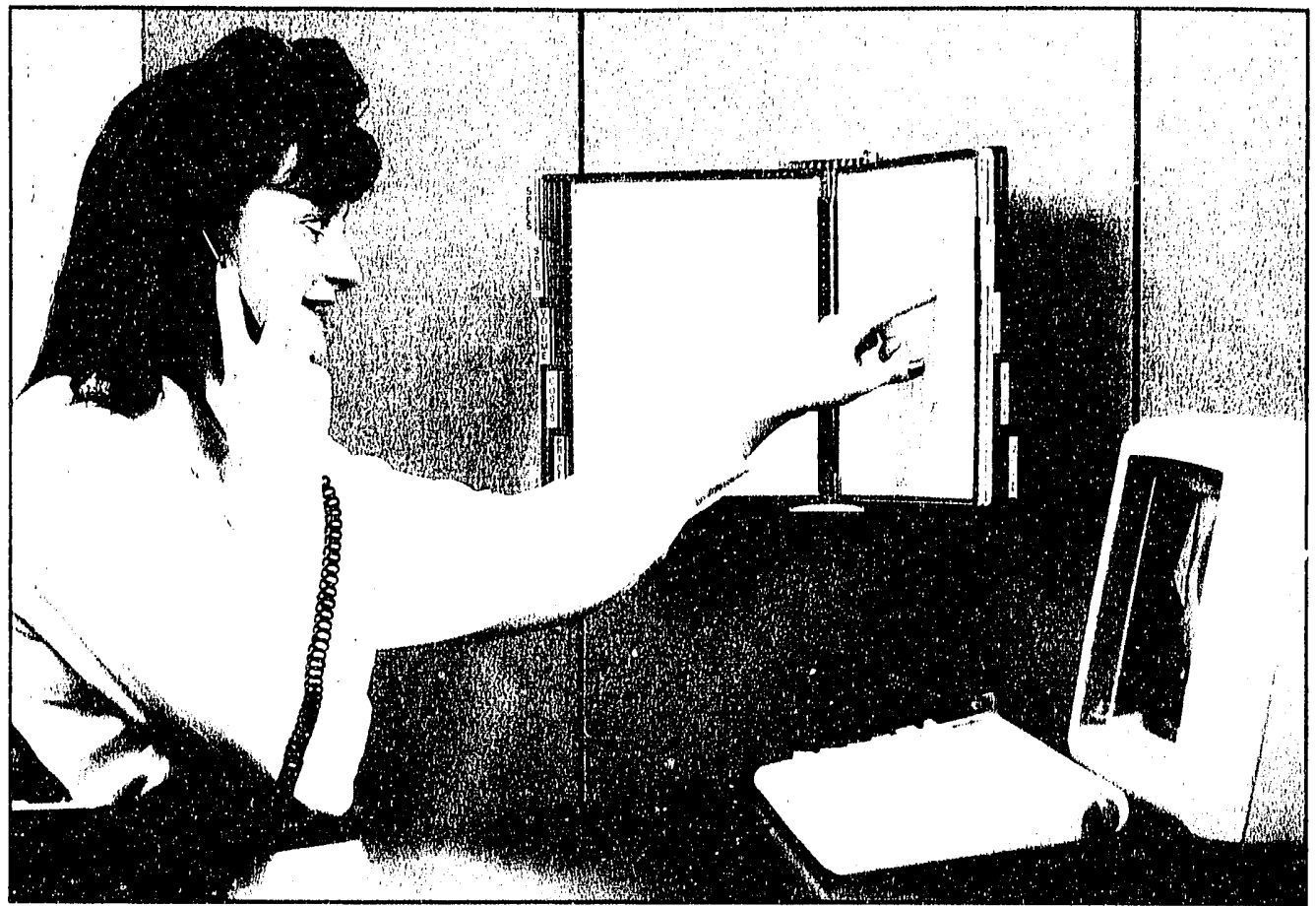

After ... with Quick-Eze Wall Unit

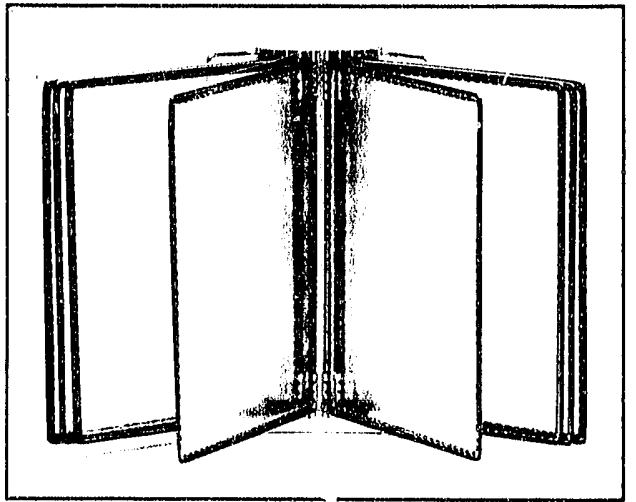

Each Quick-Eze wall system includes mounting mechanism, $81 / 2$ " $\times 11$ " pop-in, pop-out transparent pockets, and pocket tabs for fast referencing.

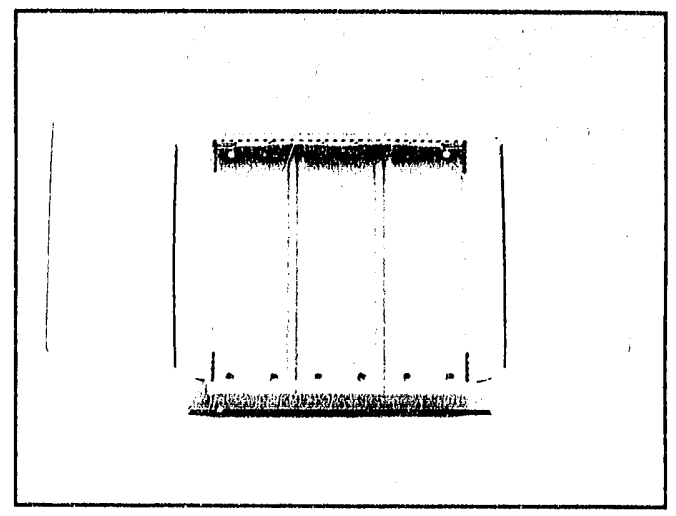

Place as many wall mechanisms side by side to increase reference sheet capacity at any time. (Photo shows 3 wall units).

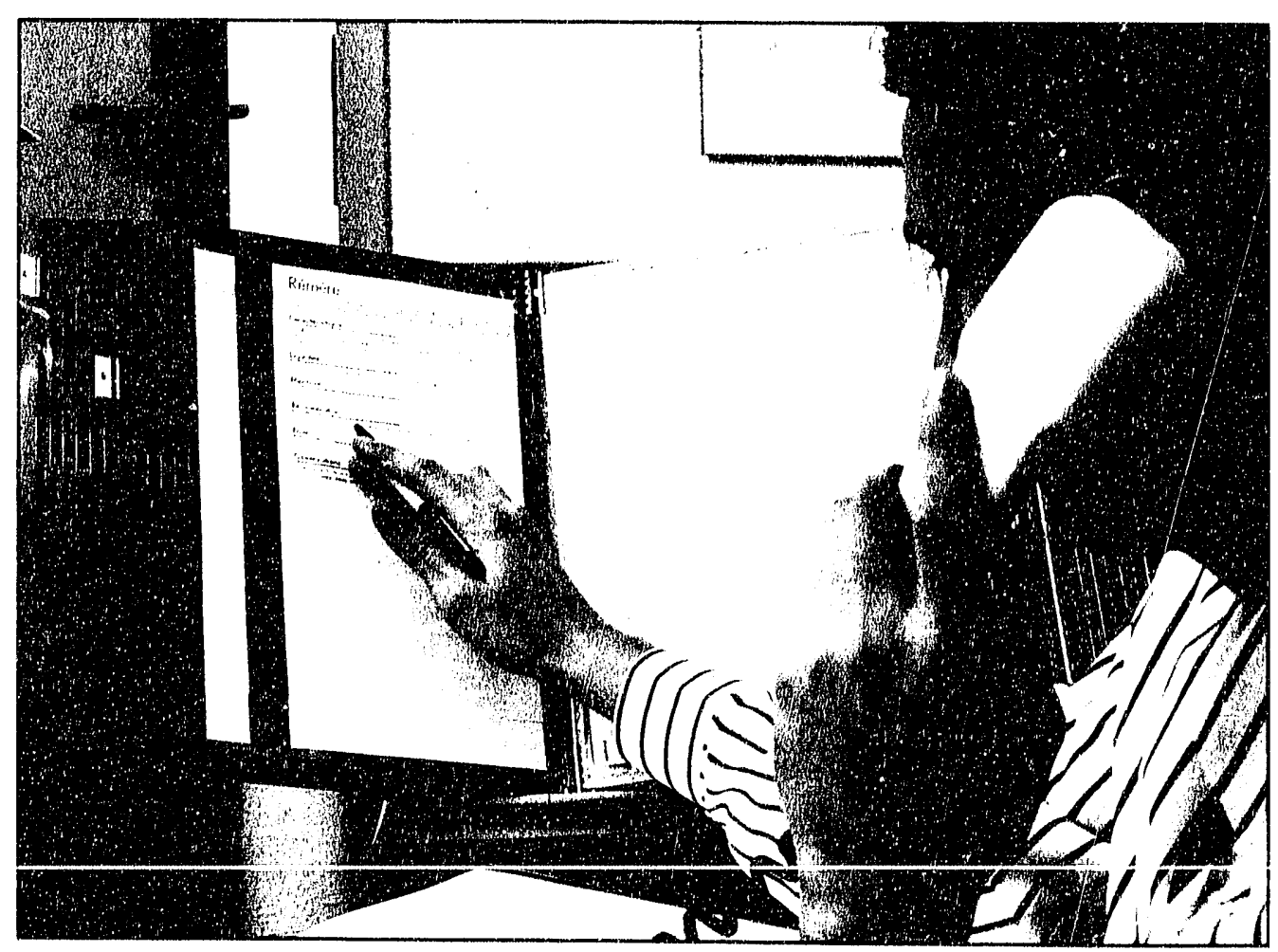




\section{QUICK-EZE USERS INCLUDE}

SERVICE COMPANIES

Ocean Propertios Management

Ponsion \& Sorvices Group Holiday lnin

Alpona Travel Sorvice

MacPherson Funeral Home

HOSPITALS

NC Baptist Hospital

Montor Hospital

Jefferson General Hos pital

Boulevard Health Service

Flint Medical Labs

Mercy Hospital

Eyo Care Norh

Hess Memorial Hospital

\section{SCHOOLS}

Dorothy Nolan School

Knox County School

Lewiston Elementary

Sullivan County

Union Free School District

Board of Ed, Saratoga Springs

University of Missouri
UTILITIES

Consumers Power

Biocklyn Union Gas

Florida Eleotric

Sturgeon Bay Utilities

Florida Power \& Light

MANUFACTURERS

Anhouser Busch

General Electric

Xerox Corp.

Texaco

Genie industries

Sander Manulacturing

Circlo Soal Controls

Hartford Stream Boiler

GOVERNMENT AGENCIES

Minnesota Dept of Tran

Clty of Long Boach

City of Ocean

California DOT

Bediord Solid Waste

Sheppard A.F.B

Naval Sub Base
'We tried I Quickeze q)esktop. Sigtem ard the time savings alone. has been unbefieviafle. Nou all 35 of our (iustomer Service Agents can fiandle incoming calls quickly and efficiently. Information that we nomally kept in file drawers or all over our desk is nou easily accessible and ready for reference."

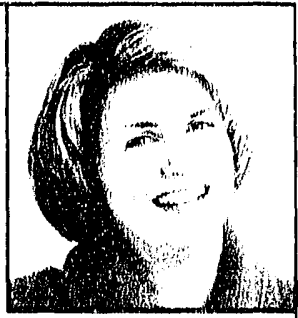

Mary Montgomery Service Mannager Waterford Crystal

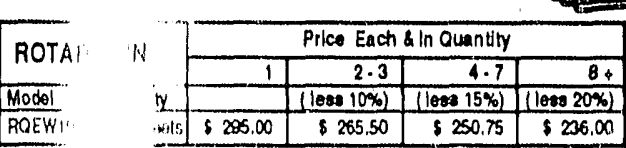

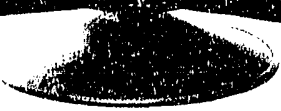

\section{JCK-ZZ Quick Information \& Easy Access Saves Everyone Time}

1)
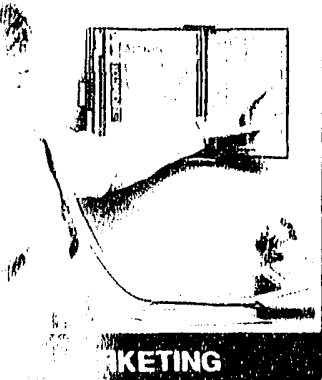

thools,

Hons:

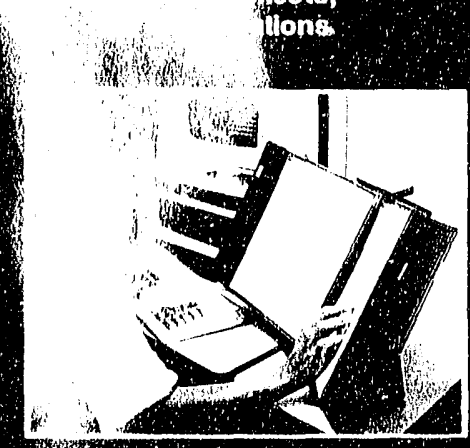

6) WolaL Banks,

Insuranos itito sind Brokers

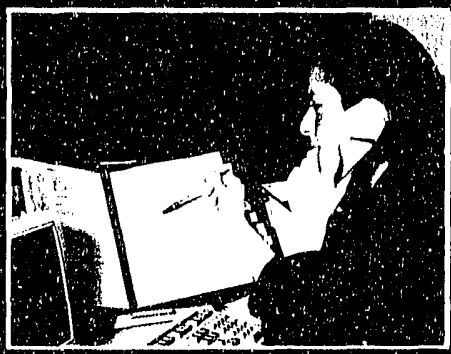

TELEMARKETING / CUSTOMER SEAVICE Scripts, Call Guides, Product Benelits, Shipping Rales.

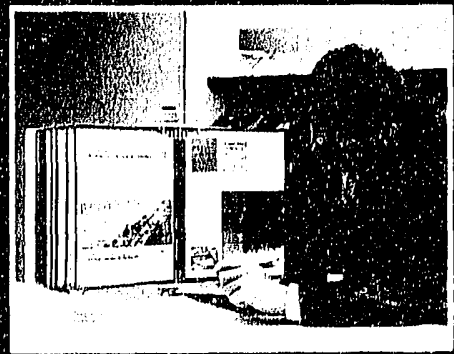

UTERATUAE DISPLAYS Travel Argenolos Eutalog eoublatios Doctor and Denilst old

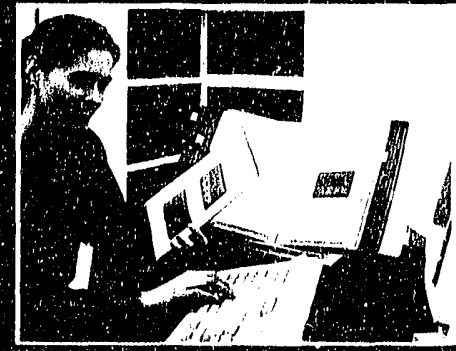

DATA PROCESSING Manuals. Koy Codes, instructions, Menus Directorios.

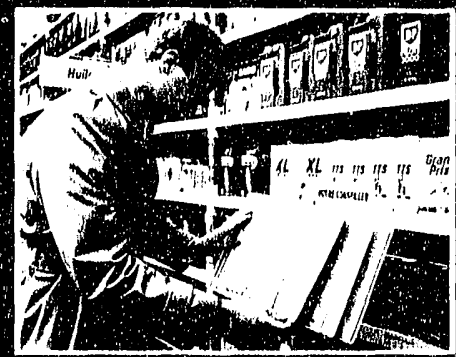

Aetail Chock Outs, Parts,

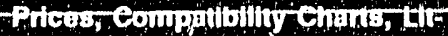
oralure, Samplas.

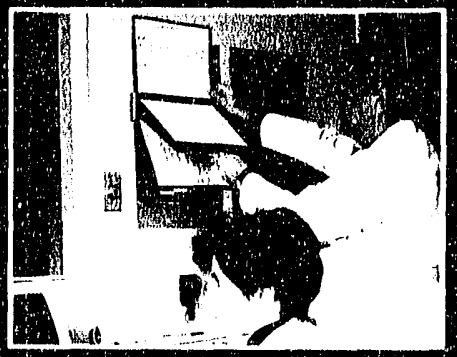

Hospitals schedules, Pallont Charts; Adinissions and Bod Conirol Stalling

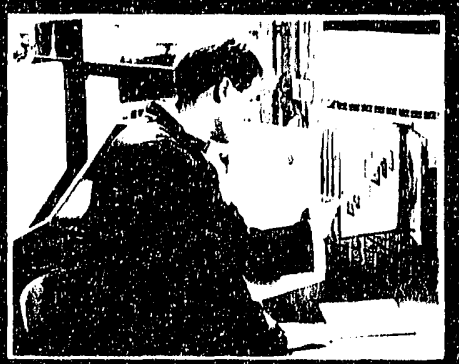

PAODUCTION Inventory sheels,

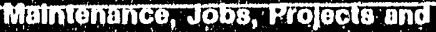
Procedures. 


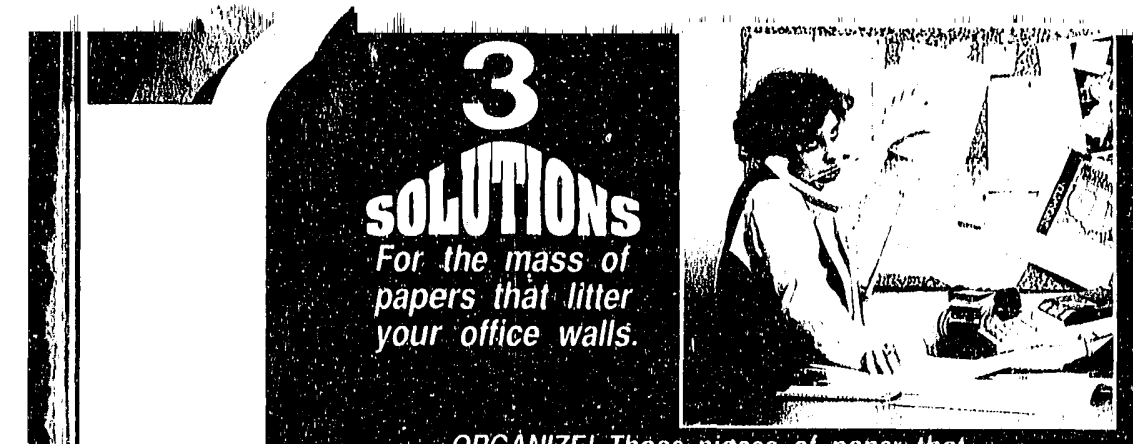

ORGANIZE! Those pieces of paper that You Look at Everyday!
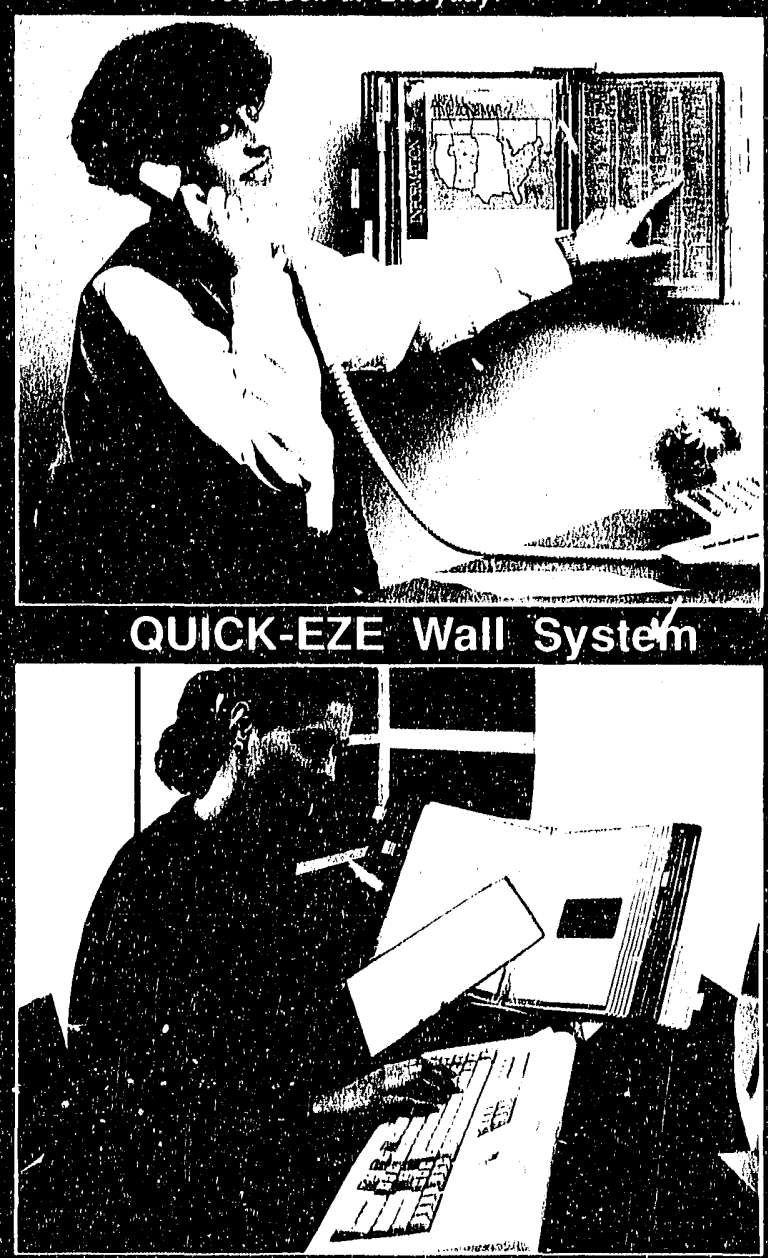

QUICK-EZE Desk System

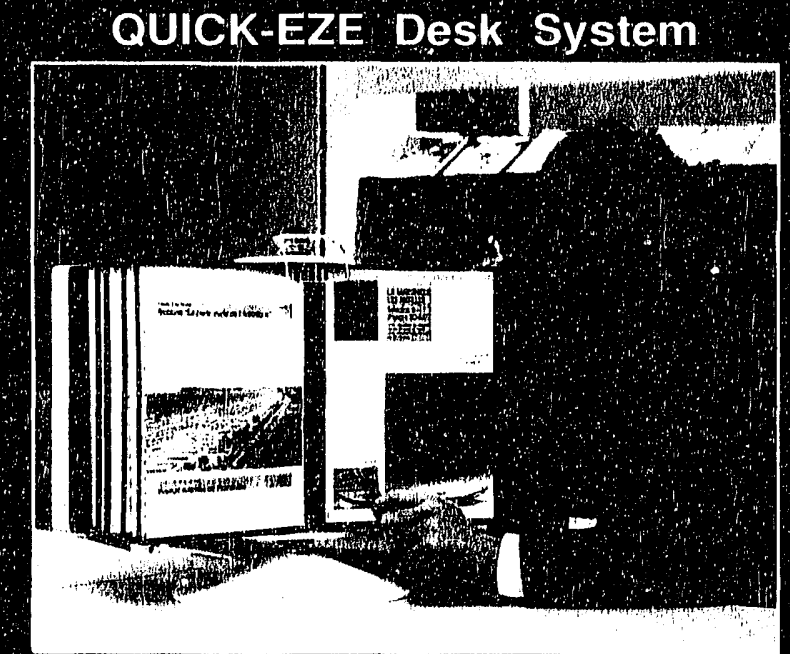

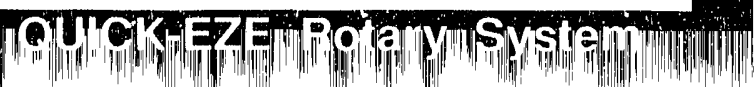

\section{1}

\section{A.}

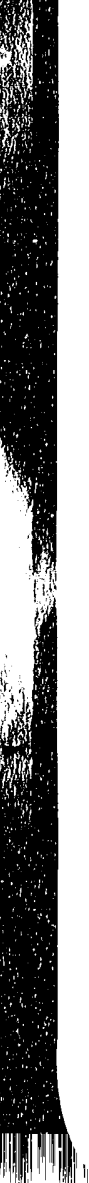

ABBOT OFFICE SYSTEMS

600 ASBURY AVENUE...FARMINGDALE, NJ 07727 (908) 938.6000

TOLL FREE 800.631-2233 „.. FAX (908) 938-4419
BULL RATE
U.S. POSTAQE
PAID
ABEOT OFFICE
SYSTEMS

e

\section{QUIGK-EZE One-Piece \\ Steelwire Pocket Frames}

Keeps pookels rigid while still being flexible of your wall, desk or rotary mounting mechanisms.

- Sieel Pocket Pivóts won break off pages lurn. easily \& effortiessly.

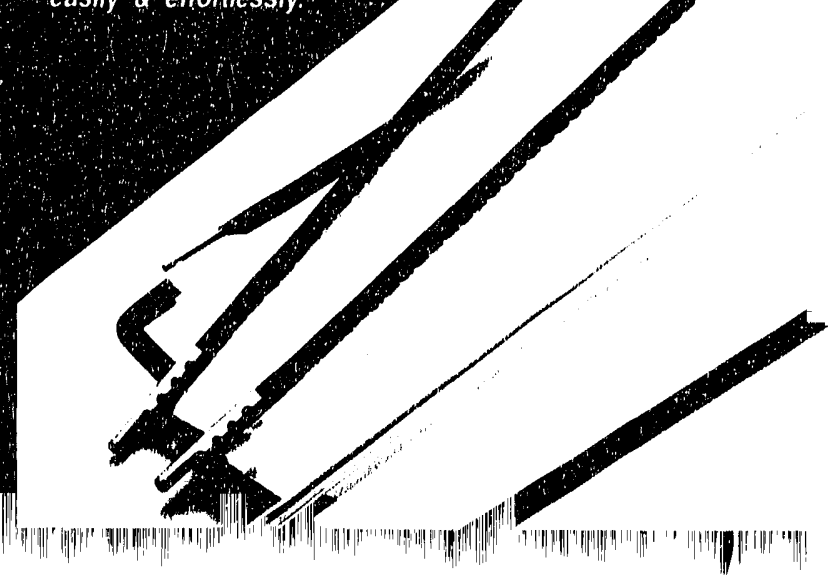



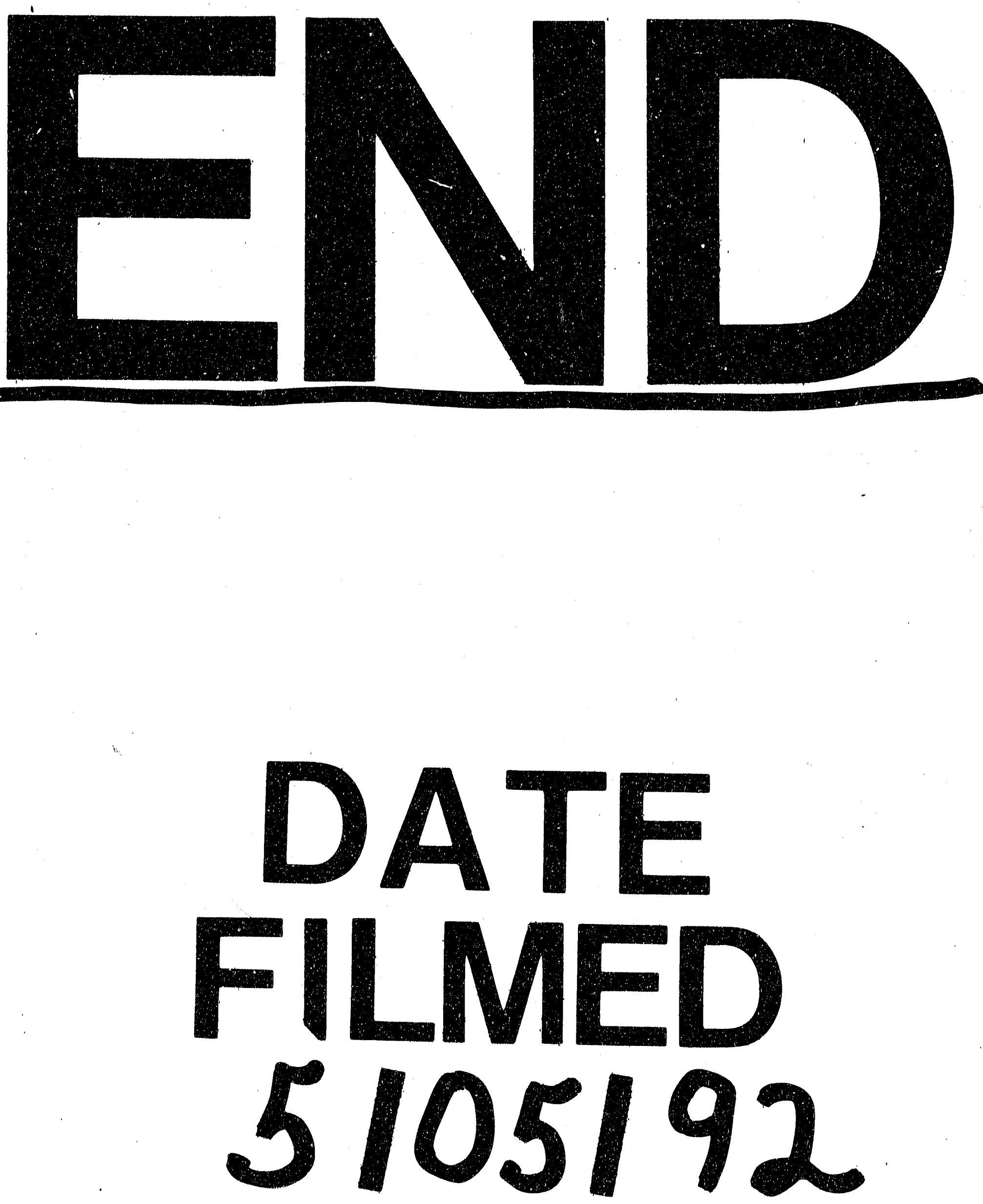

1 


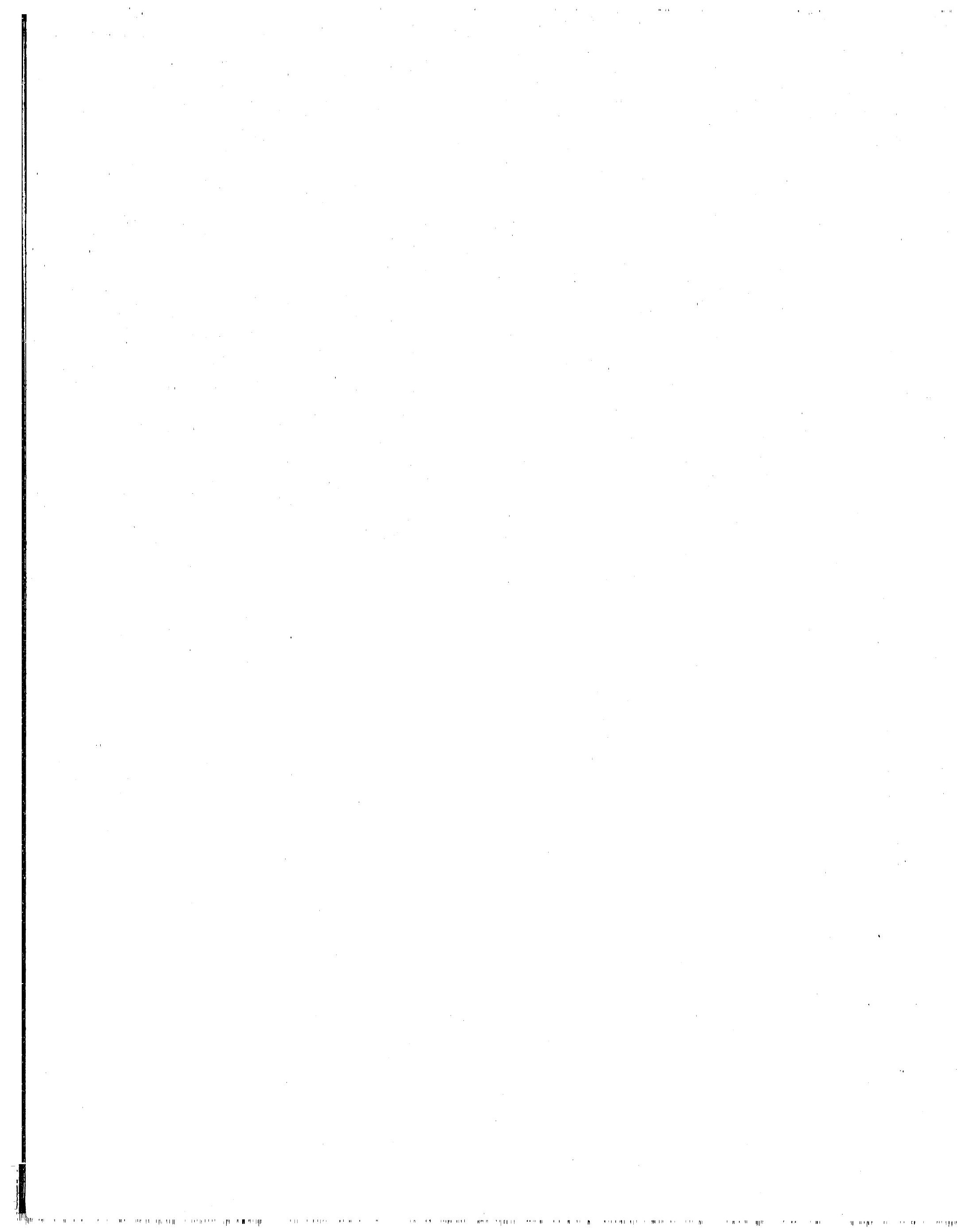

